\title{
A case-control study of exposure to organophosphate flame retardants and risk of thyroid cancer in women
}

\author{
Nicole C. Deziel ${ }^{1 *}$ DD, Huangdi $\mathrm{Yi}^{1,4}$, Heather M. Stapleton ${ }^{2}$, Huang Huang ${ }^{3}$, Nan Zhao ${ }^{1}$ and Yawei Zhang ${ }^{1,3}$
}

\begin{abstract}
Background: Growing evidence demonstrates that exposure to organophosphate flame retardants (PFRs) is widespread and that these chemicals can alter thyroid hormone regulation and function. We investigated the relationship between PFR exposure and thyroid cancer and whether individual or temporal factors predict PFR exposure.
\end{abstract}

Methods: We analyzed interview data and spot urine samples collected in 2010-2013 from 100 incident female, papillary thyroid cancer cases and 100 female controls of a Connecticut-based thyroid cancer case-control study. We measured urinary concentrations of six PFR metabolites with mass spectrometry. We estimated odds ratios (OR) and $95 \%$ confidence intervals $(95 \% \mathrm{Cl})$ for continuous and categories (low, medium, high) of concentrations of individual and summed metabolites, adjusting for potential confounders. We examined relationships between concentrations of PFR metabolites and individual characteristics (age, smoking status, alcohol consumption, body mass index [BMI], income, education) and temporal factors (season, year) using multiple linear regression analysis.

Results: No PFRs were significantly associated with papillary thyroid cancer risk. Results remained null when stratified by microcarcinomas (tumor diameter $\leq 1 \mathrm{~cm}$ ) and larger tumor sizes $(>1 \mathrm{~cm}$ ). We observed higher urinary PFR concentrations with increasing BMI and in the summer season.

Conclusions: Urinary PFR concentrations, measured at time of diagnosis, are not linked to increased risk of thyroid cancer. Investigations in a larger population or with repeated pre-diagnosis urinary biomarker measurements would provide additional insights into the relationship between PFR exposure and thyroid cancer risk.

Keywords: Thyroid cancer, Flame retardants, Endocrine disruptor, Women's health, Environmental exposures, Biomarkers

\section{Background}

Thyroid cancer is the most common endocrine malignancy worldwide and is three times more common in women compared to men $[1,2]$. The age-adjusted annual incidence rate for thyroid cancer in women in the United States (U.S.) nearly tripled over the previous twenty years, from $7.7 / 10^{5}$ in 1991 to $22.2 / 10^{5}$ in 2014 in women [1]. Papillary thyroid carcinoma accounts for approximately $90 \%$ of all thyroid cancer cases in the United States [1].

\footnotetext{
* Correspondence: nicole.deziel@yale.edu

${ }^{1}$ Department of Environmental Health Sciences, Yale School of Public Health, 60 College St, New Haven, CT 06520, USA

Full list of author information is available at the end of the article
}

Though the prognosis for thyroid cancer is quite good ( $>90 \%$ survival after 20 years) [1], the costs for diagnosis, treatment, and continued surveillance are significant, estimated at $\$ 1.6$ billion for all U.S. patients diagnosed after 1985 [3]. With the incidence rate climbing rapidly, projected societal costs for 2030 exceed $\$ 3.5$ billion. Furthermore, thyroid cancer is associated with an increased risk of developing a second primary cancer, potentially attributable to radiation-based treatments such as radioiodine or directed beam radiation therapy $[4,5]$. The quality of life of thyroid cancer survivors may be impaired due to co-morbidities and dependence on long-term treatment [6].

(c) The Author(s). 2018 Open Access This article is distributed under the terms of the Creative Commons Attribution 4.0 International License (http://creativecommons.org/licenses/by/4.0/), which permits unrestricted use, distribution, and 
The etiology of thyroid cancer is largely unknown. The major established causal factor is exposure to ionizing radiation during childhood [7, 8]; other risk factors include family history of thyroid cancer, personal history of benign thyroid diseases [9], and greater body weight and height $[10,11]$. These known and suspected risk factors explain only a small portion of thyroid cancer cases. Changes in diagnostic procedures and increased medical attention to thyroid nodules explain part of the rise during the past two decades [12-14]. However, reported incidence rates have increased across all tumor sizes [15, $16]$, in younger age groups that are less likely to receive imaging exams [17, 18], and for follicular thyroid cancer, which is less easily detected by newer diagnostic technologies [19]. Taken together, this supports the role of other factors in addition to increased detection [20]. Environmental and occupational exposures to chemicals have been proposed as potentially important contributors to the increasing trend [21-24].

Organophosphate flame retardants have been commonly used in the 1990s and 2000s, and their use has been increasing due to the phase out of the polybrominated diphenyl ether (PBDE) flame retardants [25-27]. Firemaster $550^{\circ}$, a mixture of phosphorous-containing compounds including triphenyl phosphate (TPHP), has gained popularity as an additive to polyurethane foam [26, 28, 29]. Tris (1,3-dichloro-isopropyl) phosphate (TDCPP), previously restricted from use in children's pajamas in the 1970s due to concerns of carcinogenicity (linked to tumor formation in liver, kidney, and testes of rodents), also has been commonly used in polyurethane foam and has increasingly been used as a replacement for PBDEs [30]. These organophosphate esters have also been used as plasticizers and lubricants in various consumer products $[27,31,32]$.

Little is known about exposures to these organophosphate esters. Emerging studies of exposure to TDCPP and Firemaster $550^{\circ}$ have observed widespread concentrations in house dust samples worldwide [27, 28]; concentrations tend to vary by home and by geographic region [28, 33]. Recent biomonitoring studies have demonstrated that exposures are ubiquitous among U.S. adults [34-36]. Individual characteristics predictive of higher exposures to PFRs are not well-established, and the previous biomonitoring studies have focused primarily on pregnant women and mother-child pairs [35, 37-40]. Further elucidation of determinants of increased exposures to PFRs and the mechanisms underlying observed variability across individuals are important for potential exposure mitigation efforts and for interpreting biological monitoring data in epidemiologic studies.

PFRs have been associated with perturbations in thyroid hormone concentrations in preliminary experimental studies, with some sex-specific and compound-specific differences in the direction of the effect. Toxicological results with zebrafish and chicken embryos suggests TDCPP and TPHP have the potential to alter thyroid hormone regulation and synthesis [41-44]. Xu et al. observed a significant reduction in plasma thyroxine (T4) and triiodothyronine (T3) with TDCPP exposure in female, but not male zebrafish $[45,46]$. Liu et al. reported long-term exposure to TPHP increased T3 and T4 in zebrafish [47]. A recent in vitro study observed influences on thyroid hormone transport through enhanced binding of T4 to the transport protein transthyretin in response to exposure to 6 PFRs [48]. Human studies evaluating the role of these PFR and thyroid function is quite limited with differing results. A study of U.S. men recruited from an infertility clinic observed that higher concentrations of TDCPP in house dust were linked to lower levels of T4 $(n=50)$ [49]; this association was not confirmed in an exploratory study with biological monitoring of urinary PFR metabolites in a subset of this population $(n=33)$ [50]. Preston et al. observed an association between urinary concentrations of TPHP metabolites and increased levels of T4, particularly in women ( $n=52$ U.S. men and women) [51]. Although there is a lack of direct evidence linking PFRs to thyroid cancer risk, altered thyroid hormone and thyroid stimulating hormone (TSH) levels have been associated with the risk of thyroid cancer. Epidemiologic evidence suggests that T3 and T4 exhibit tumor-promoting effects for other hormonally related cancers, such as ovarian, prostate, pancreatic cancers [52]. Epidemiologic studies have also observed associations between TSH and risk of thyroid cancer; a recent nested case-control study documented sex-specific differences in this relationship and the potential for increased risk of papillary thyroid cancer among individuals with TSH hormones outside of the normal range on either the low or high end $[53,54]$. In studies of laboratory animals, TSH and thyroid hormones have also been related to tumor growth [52], and high TSH levels were linked to papillary thyroid cancer initiation in a mouse model [55]. There is an urgent need to better understand whether exposure to these chemicals leads to increased thyroid dysregulation and increased cancer risk.

The objectives of this study were to advance understanding of the human exposures and health endpoints of PFRs by (1) investigating the relationship between PFR exposure and thyroid cancer in women and (2) evaluating sociodemographic and temporal predictors of PFR exposure.

\section{Methods}

\section{Study population}

The current, exploratory study included a subset of 200 female, Caucasian participants from a population-based case-control study in Connecticut. The parent study has been described previously [23, 56, 57]. Cases were 
individuals newly diagnosed with thyroid cancer from 2010 to 2011 in Connecticut, identified through the Yale Cancer Center's Rapid Case Ascertainment Shared Resource, the agent of Connecticut Tumor Registry. Eligibility criteria included being aged 21 to 84 years at diagnosis and having no previous diagnosis of cancer (except for non-melanoma skin cancer). Tumor subtypes were histologically confirmed (papillary, follicular, medullary, and anaplastic). A total of 462 cases participated (65.9\% participation rate). Population-based controls with Connecticut addresses were recruited using a random digit dialing method. Controls were frequency-matched to cases by age (+/-5 years); their participation rate was $61.5 \%$. For the current analysis, 100 female papillary thyroid cancer cases were randomly selected and 100 population-based controls were matched to these cases by gender and age (5-year age groups). We focused on women due to their higher thyroid cancer incidence compared to men and on papillary thyroid tumors because they are the most prevalent. Because the parent study population was predominantly Caucasian (90\%), we restricted the analysis to white women to reduce sources of heterogeneity in our analysis of 200 women. All study procedures were approved by the Human Investigations Committee at Yale (HIC \# 0911005954) and the Connecticut Department of Public Health.

\section{Data and sample collection}

After obtaining participants' written consent, a trained interviewer administered a standardized, structured questionnaire about demographic factors, lifestyle information, medical conditions and medication use, family medical history, occupation, and diet. After the interview, spot urine samples were collected in polypropylene collection cups and stored frozen at $-80{ }^{\circ} \mathrm{C}$ in 5 - $\mathrm{ml}$ aliquots. Interviews and urine collections were conducted from 2010 to 2013 and were scheduled at various times of day, based on participants' availability.

\section{Laboratory analysis of PFR metabolites}

For each participant, a 5-ml aliquot was analyzed for 6 PFR metabolites of the commonly used parent compounds tris(1,3-dichloro-isopropyl) phosphate and triphenyl phosphate: 1-hydroxy-2-propyl bis(1-chloro-2-propyl) phosphate (BCIPHIPP), bis(1-chloro-2-propyl) phosphate (BCIPP), diphenyl phosphate (DPHP), bis(1,3-dichloro-2-propyl) phosphate (BDCIPP), isopropyl-phenyl phenyl phosphate (ip-PPP), and tert-butyl phenyl phenyl phosphate (tb-PPP). Samples were analyzed using solid phase extraction (SPE) and enzyme deconjugation followed by liquid chromatography-tandem mass spectrometry, following a previously described, validated protocol $[34,35]$. In brief, samples were spiked with an internal standard mixture (10 ng of d10-BDCIPP, $8.8 \mathrm{ng}$ of d10-DPHP, $25 \mathrm{ng}$ of d12-TCEP) and vortexed. Sodium acetate (1.75 ml of $1 \mathrm{M}$ sodium acetate) was added to adjust the $\mathrm{pH}$ to 5 . An enzyme solution was added $(250 \mu \mathrm{l}$ of 1000 units $/ \mathrm{ml} \mu$-glucuronidase, 33 units $/ \mathrm{ml}$ sulfatase in $0.2 \mathrm{M}$ sodium acetate buffer), and samples were vortexed and incubated overnight in a $37{ }^{\circ} \mathrm{C}$ water bath. Samples were extracted and cleaned using SPE with a StrataX-AW (60 mg, $3 \mathrm{ml}$ ) column, and were reconstituted in $500 \mu \mathrm{l}$ of 1:1 water:methanol. Internal standard recovery was quantified by spiking with 13C2-DPHP. Prior to analysis, the specific gravity of the samples was measured to correct for urinary dilution using a digital handheld refractometer (Atago). The extracts were analyzed using electrospray ionization (ESI) LC-MS/MS with a Phenomenex Luna C18 column on an Agilent 1100 series LC and an Agilent 6410B tandem mass spectrometer as previously described $[34,35,37]$. Laboratory researchers were blinded to case/ control status.

Method detection limits (MDLs) were calculated as three times the standard deviation of the laboratory blanks, normalized to the average urine volume $(3 \mathrm{ml})$. Average recoveries were $110 \%$ for $\mathrm{dBDCIPP}$ and $85 \%$ for dDPHP. Laboratory blind duplicates $(n=10)$ had a mean and median coefficient of variation of 19 and 15\%. Specific gravity-corrected and uncorrected concentrations were highly correlated across the 6 metabolites $\left(r_{\text {Spear }}\right.$ man $>0.91$ ) and results were very similar; therefore only SG-corrected measurements are presented, consistent with previous studies [35, 37].

\section{Statistical analysis}

Odds ratios (ORs) and 95\% confidence intervals (CIs) were calculated using logistic regression models to estimate associations between exposures to PFRs and the risk of thyroid cancer, while controlling for potential confounders. Potential confounding variables included in the final model were age $(<40,40-49,50-59,60-69$, $\geq 70$ ), body mass index (BMI, $<25,25-29.99, \geq 30$ ), education level, family history of thyroid cancer, previous benign thyroid disease (hyper- or hypothyroidism), and alcohol consumption (lifetime consumption of $\leq 12$ alcoholic drinks vs. $>12$ drinks). Adjustment for other variables, such as family income, smoking, and season of interview did not result in a 10\% change in the ORs, and thus they were not included in the final models.

We modeled categories of exposure to individual and summed PFRs and thyroid cancer risk using tertiles, based on the distribution among controls, for the four compounds detected in $>97 \%$ of samples (DPHP, BDCIPP, ip-PPP, BCIPHIPP). We categorized BCIPP, detectable in only $46 \%$ of samples, as $<\mathrm{MDL}$, $\leq$ median of detectable values, and $>$ median of detectable values, using the median among controls. tb-PPP was only 
detected in $6 \%$ of samples and was therefore excluded from further statistical analyses. Tests for trend were based on trisected chemical concentrations in the regression models. For the compounds detectable in > 97\% of samples, we also modeled the continuous concentrations of individual and summed PFRs (natural log-transformed), replacing values $<\mathrm{MDL}$ with one-half the detection limit. We also conducted analyses stratified by tumor size (tumor diameter $\leq 1 \mathrm{~cm}$ [microcarcinoma] and $>1 \mathrm{~cm}$ ). All tests of statistical significance were two-sided with an alpha of 0.05 . Analyses were conducted using $\mathrm{R}$ (version 3.2.4, platform x86_64-apple-darwin13.4.0).

We used multiple linear regression models to examine the relationship between natural log-transformed concentrations of PFR metabolites and self-reported individual characteristics (age, smoking status, alcohol consumption, BMI, income, education) and temporal factors (date of sample collection [continuous measure scaled to years] and season of collection [DecemberFebruary, March-May, June-August, September-November]). We used step-wise backward elimination to construct models with covariates of $p$-values $<0.1$, a benchmark commonly used in exposure determinants analyses.

\section{Results}

Exposure to PFRs was ubiquitous in our study population (Table 1). ip-PPP was present at the highest concentrations, with a median concentration and interquartile range (IQR) of $2.35 \mathrm{ng} / \mathrm{ml}(1.33-4.51)$ across all samples, followed by DPHP (median $=0.82 \mathrm{ng} / \mathrm{ml}$, IQR $=0.49-$ 1.5), BDCIPP (median $=0.65 \mathrm{ng} / \mathrm{ml}, \mathrm{IQR}=0.31-1.6$ ), and BCIPHIPP (median $=0.19 \mathrm{ng} / \mathrm{ml}$, IQR $=0.09-0.45$ ). Concentrations were similar between cases and controls (Table 1). The concentrations of the specific-gravity corrected PFRs were weakly correlated with each other $\left(r_{\text {Spearman }}=0.11-0.30 ;\right.$ median $=0.21$; correlations were moderate among uncorrected values (median $r_{\text {Spearman }}=$ 0.19-0.44; median $=0.27$ ) (Additional file 1: Table S1a and $1 \mathrm{~b})$.
The distributions of demographic characteristics of the female papillary thyroid cancer cases and controls are presented in Table 2. Compared with controls, cases were less educated $(p$-value $=0.009)$ and were more likely to have a previous benign thyroid disease $(p$-value $=0.02)$. Distributions of family income, and smoking status were similar among cases and controls.

None of the individual PFRs were positively associated with risk of papillary thyroid cancer, based on categorical and continuous forms of the exposure variables (Table 3). The odds ratios for BCIPP presented a suggestion of an inverse association with thyroid cancer risk; however all 95\% confidence intervals included the null ( $p$-value for trend $=0.06$ ). Results stratified by tumor sizes were also generally null (Table 4). The odds ratios comparing the highest to lowest exposure categories for the larger tumor sizes suggested an elevated risk for DPHP, BDCIPP, IPDPP; however, confidence intervals were wide.

Our exposure determinants analysis demonstrated a relationship between higher BMI and two of the urinary PFR metabolite concentrations (BDCIPP, ip-IPP) (Table 5). Compared to women in the normal BMI categories, women in the obese BMI categories had approximately 1.7-times higher levels of all the PFRs and summed PRF. We observed lower concentrations of BCIPP and the summed PFRs in 2011-2013 compared to 2010. We observed some seasonal differences with BDCPP, ip-IPP and the summed PFR concentrations highest in summer and lowest in winter. Ever smokers had lower concentrations of BDCIPP and ever alcohol consumers had higher concentrations of DPHP. No associations with age, income, or education were observed.

\section{Discussion}

To our knowledge, this is the first study evaluating biomarkers of exposure to PFRs and risk of thyroid cancer. In our analysis of adult women, we found no association between exposure to PFRs and risk of papillary thyroid cancer. We observed that urinary PFR levels vary by season and BMI.

Table 1 Distributions of concentrations of urinary metabolites of organophosphate flame retardants (ng/ml; specific gravitycorrected) in female papillary thyroid cancer cases and controls

\begin{tabular}{|c|c|c|c|c|c|c|}
\hline \multirow{2}{*}{$\begin{array}{l}\text { Flame } \\
\text { retardant }\end{array}$} & \multirow[t]{2}{*}{ MDL } & \multirow{2}{*}{$\begin{array}{l}\% \\
\text { Detected }\end{array}$} & \multicolumn{2}{|c|}{ Cases $(n=100)$} & \multicolumn{2}{|c|}{ Controls $(n=100)$} \\
\hline & & & Median & 25th-75th Percentile & Median & 25th-75th Percentile \\
\hline BCIPP & 0.185 & 44.5 & 0.242 & $<\mathrm{MDL}-0.280$ & $<\mathrm{MDL}$ & $<\mathrm{MDL}-0.705$ \\
\hline DPHP & 0.104 & 97 & 0.802 & $0.457-1.549$ & 0.843 & $0.506-1.450$ \\
\hline BDCIPP & 0.046 & 97.5 & 0.729 & $0.344-1.777$ & 0.604 & $0.276-1.336$ \\
\hline ipPPP & 0.020 & 100 & 2.569 & $1.361-4.758$ & 2.251 & $1.300-4.201$ \\
\hline BCIPHIPP & 0.001 & 99.5 & 0.160 & $0.084-0.377$ & 0.214 & $0.093-0.564$ \\
\hline
\end{tabular}

bis(1-chloro-2-propyl)1-hydroxy-2-propyl phosphate (BCIPHIPP), bis(1-chloro-2-propyl) phosphate (BCIPP), diphenyl phosphate (DPP), bis(1,3-dichloro-2-propyl) phosphate (BDCIPP), isopropyl-phenyl phenyl phosphate (ip-PPP), and tert-butyl phenyl phenyl phosphate (tb-PPP), MDL (method detection limit) 
Table 2 Distribution of selected characteristics of the papillary thyroid cancer cases and controls

\begin{tabular}{|c|c|c|c|}
\hline & Cases $(n=100)$ & $\begin{array}{l}\text { Control } \\
(n=100)\end{array}$ & \\
\hline & $\mathrm{N}$ or $\%^{\mathrm{a}}$ & $\mathrm{N}$ or $(\%)^{\mathrm{a}}$ & $p$-value ${ }^{b}$ \\
\hline Age & & & 0.47 \\
\hline$<40$ & 23 & 17 & \\
\hline $40-49$ & 24 & 28 & \\
\hline $50-59$ & 39 & 31 & \\
\hline $60-69$ & 19 & 15 & \\
\hline$>=70$ & 4 & 9 & \\
\hline Years of education & & & 0.009 \\
\hline High school or less & 25 & 9 & \\
\hline $\begin{array}{l}\text { College/Technical } \\
\text { school }\end{array}$ & 47 & 55 & \\
\hline $\begin{array}{l}\text { Graduate/Professional } \\
\text { school }\end{array}$ & 25 & 35 & \\
\hline Other & 3 & 1 & \\
\hline Family income & & & 0.83 \\
\hline Below poverty level & 6 & 5 & \\
\hline Above poverty level & 71 & 68 & \\
\hline Unknown & 23 & 27 & \\
\hline BMl & & & 0.18 \\
\hline$<25$ & 32 & 38 & \\
\hline $25-29.99$ & 32 & 38 & \\
\hline$>=30$ & 36 & 24 & \\
\hline $\begin{array}{l}\text { Family history of } \\
\text { thyroid cancer }\end{array}$ & & & 0.39 \\
\hline No & 49 & 49 & \\
\hline Thyroid Cancer & 16 & 10 & \\
\hline Other Cancer & 35 & 41 & \\
\hline Thyroid disease & & & 0.02 \\
\hline Yes & 14 & 4 & \\
\hline No & 86 & 96 & \\
\hline Smoking & & & 0.76 \\
\hline Yes & 29 & 32 & \\
\hline No & 71 & 68 & \\
\hline Alcohol consumption & & & 0.20 \\
\hline Yes & 37 & 47 & \\
\hline No & 63 & 53 & \\
\hline Tumor diameter & & & - \\
\hline$\leq 1 \mathrm{~cm}$ & 47 & - & \\
\hline$>1 \mathrm{~cm}$ and $\leq 2 \mathrm{~cm}$ & 29 & - & \\
\hline$>2 \mathrm{~cm}$ & 22 & - & \\
\hline Not available & 2 & - & \\
\hline
\end{tabular}

${ }^{a}$ The frequency and percentage are equivalent because the number of cases and controls each equals 100

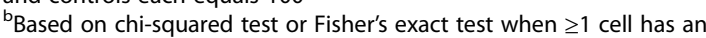
expected frequency $\leq 5$
In general, the concentrations of PFR metabolites in our adult, female Connecticut population (2010-2013) were lower than those observed in adults (mostly pregnant women) in other time frames and geographic areas, as reviewed in a recent study [58]. The exception was ip-PPP; our observed concentrations were similar or higher to the few recent cohorts measuring that specific compound. The lower observed concentrations in urinary PFR metabolites in our study could be attributable to differences in toxicokinetics (e.g., kidney function) or exposure patterns among our population of women, who were not pregnant and had median age 10-20 years greater than the previous studies of pregnant women. Differences could also reflect geographic variations in flammability standards.

Exposure to PFRs was widespread in our population. Our exposure determinants analysis revealed associations between higher PFR concentrations and increased BMI. Possible explanations include the obesogenic potential of PFRs themselves [59] or common activities or behaviors leading to both higher BMI and higher exposure [58]. Neither income nor education were linked to urinary PFR concentrations; however, the participants were generally white, well-educated women living above the poverty line, reducing our power to fully examine these demographic patterns. We also observed a strong seasonal pattern, with higher urinary PFR levels in the summer, consistent with a previous exposure determinants analysis [58]. This relationship could reflect increased volatilization of PFRs and subsequent increased inhalation exposure in warmer months [60], increased dermal exposure due to greater surface area of exposed skin and increased perspiration, or possibly incomplete adjustment for relative dehydration in summer months (i.e., lower dilution of samples), although all samples were corrected for specific gravity.

Our study has several strengths, including its novel study question, population-based study design, and rapid and thorough identification of incident cases using the Connecticut Tumor Registry. All the cases were histologically confirmed to minimize misclassification of outcomes; information on tumor size was available for analysis. Detailed information on potential confounding factors were collected and controlled for in the analysis. Finally, the use of a biological marker of PFR exposure is an objective exposure measure. Finally, our study provides additional exposure data on these ubiquitous, endocrine-disrupting chemicals.

Several limitations warrant consideration. The most important is that our samples were collected post-diagnosis. As with all retrospective case-control studies of biomarkers and chronic disease, the exposures may not be representative of past exposure during etiologically relevant time windows, which have not yet been 
Table 3 Adjusted and unadjusted odds ratios and 95\% confidence intervals for the association of urinary concentrations of organophosphate flame retardants ( $\mathrm{ng} / \mathrm{ml}$; specific gravity-corrected) and papillary thyroid cancer in Connecticut women

\begin{tabular}{|c|c|c|c|c|c|c|}
\hline Organophosphate flame retardant (ng/ml) & Cases & Controls & Unadjusted OR (95\% Cl) & $\mathrm{p}$ - trend & Adjusted OR $(95 \% \mathrm{Cl})^{\mathrm{a}}$ & p-trend \\
\hline \multicolumn{7}{|l|}{ BCIPP } \\
\hline$<\mathrm{MDL}$ & 61 & 50 & 1 & & 1 & \\
\hline$\geq \mathrm{MDL}-0.45$ & 26 & 25 & $0.85(0.44,1.66)$ & & $0.72(0.34,1.54)$ & 0.06 \\
\hline$>0.45$ & 13 & 25 & $0.43(0.19,0.91)$ & 0.04 & $0.44(0.18,1.03)$ & \\
\hline Continuous $^{\mathrm{b}}$ & 100 & 100 & $0.88(0.77,1.01)$ & & $0.89(0.76,1.04)$ & \\
\hline \multicolumn{7}{|l|}{ DPHP } \\
\hline$<0.59$ & 34 & 33 & 1 & & 1 & \\
\hline $0.59-1.28$ & 34 & 33 & $1.00(0.51,1.97)$ & & $1.02(0.47,2.22)$ & 0.88 \\
\hline$>1.28$ & 32 & 34 & $0.91(0.46,1.80)$ & 0.80 & $1.06(0.49,2.29)$ & \\
\hline Continuous $^{\mathrm{b}}$ & 100 & 100 & $0.94(0.72,1.21)$ & & $0.99(0.74,1.31)$ & \\
\hline \multicolumn{7}{|l|}{ BDCIPP } \\
\hline$<0.37$ & 31 & 33 & 1 & & 1 & \\
\hline $0.37-0.96$ & 28 & 33 & $1.17(0.59,2.35)$ & & $1.08(0.50,2.36)$ & 0.46 \\
\hline$>0.96$ & 41 & 34 & $1.24(0.63,2.46)$ & 0.54 & $1.33(0.62,2.86)$ & \\
\hline Continuous $^{\mathrm{b}}$ & 100 & 100 & $1.07(0.87,1.31)$ & & $1.07(0.85,1.34)$ & \\
\hline \multicolumn{7}{|l|}{ IPDPP } \\
\hline$<1.60$ & 32 & 33 & 1 & & 1 & \\
\hline $1.60-3.56$ & 26 & 33 & $0.90(0.45,1.83)$ & & $0.89(0.41,1.59)$ & 0.66 \\
\hline$>3.56$ & 42 & 34 & $1.28(0.66,2.51)$ & 0.45 & $1.17(0.54,2.54)$ & \\
\hline Continuous $^{\mathrm{b}}$ & 100 & 100 & $1.12(0.83,1.52)$ & & $1.06(0.75,1.48)$ & \\
\hline \multicolumn{7}{|l|}{ BCIPHIPP } \\
\hline$<0.12$ & 38 & 33 & 1 & & 1 & \\
\hline $0.12-0.32$ & 34 & 33 & $0.89(0.46,1.75)$ & & $0.92(0.44,1.93)$ & 0.30 \\
\hline$>0.32$ & 28 & 34 & $0.72(0.36,1.41)$ & 0.34 & $0.66(0.30,1.42)$ & \\
\hline Continuous $^{\mathrm{b}}$ & 100 & 100 & $0.85(0.69,1.03)$ & & $0.82(0.65,1.01)$ & \\
\hline \multicolumn{7}{|l|}{ Summed PFR } \\
\hline$<4.10$ & 35 & 34 & 1 & & 1 & \\
\hline $4.10-7.95$ & 29 & 33 & $0.85(0.43,1.70)$ & & $0.94(0.43,2.00)$ & \\
\hline$>7.95$ & 36 & 33 & $1.06(0.54,2.07)$ & 0.87 & $1.07(0.50,2.31)$ & 0.86 \\
\hline Continuous $^{\mathrm{b}}$ & 100 & 100 & $0.96(0.71,1.31)$ & & $0.93(0.65,1.33)$ & \\
\hline
\end{tabular}

bis(1-chloro-2-propyl) 1-hydroxy-2-propyl phosphate (BCIPHIPP), bis(1-chloro-2-propyl) phosphate (BCIPP), diphenyl phosphate (DPP), bis(1,3-dichloro-2-propyl) phosphate (BDCIPP), isopropyl-phenyl phenyl phosphate (IP-PPP), and tert-butyl phenyl phenyl phosphate (tb-PPP), odds ratio (OR), $95 \%$ confidence interval (95\% CI), PFR (organophosphate flame retardant)

${ }^{a}$ Adjusted for age, BMI, education level, family history of thyroid cancer, previous benign thyroid disease, and alcohol consumption

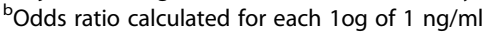

established for thyroid cancer. Additionally, measurements of PFRs in spot urine collections may not be representative of usual, long-term exposure due to their short half-lives. Intra-class correlation coefficients for repeated urinary BDCIPP and DPHP concentrations measured over 3 to 9 months range from 0.3 to $0.7[36,61]$. The resulting misclassification from post-diagnosis, spot urine samples would likely attenuate risk estimates. Unfortunately, no long-term biomarkers of exposure exist. Another potential limitation with a post-diagnosis urine sample is that disease status or chemo- or radio-therapy could affect the concentrations of PFRs, though we do not expect this. Unlike other cancer sites, papillary thyroid cancer patients are treated either by surgery alone or surgery and postoperative ${ }^{131}$ I treatment. This is an extremely effective and specific treatment for thyroid cancer; no other organs or cells are affected by the radioactive iodine. As such, the treatment for papillary thyroid cancer patients is less likely to affect the urinary levels of PFRs. A nested case-control or cohort study with repeated samples would be needed to overcome these limitations. Measurement of PFRs in residential 
Table 4 Odds ratios and 95\% confidence intervals for the association of urinary concentrations of organophosphate flame retardants ( $\mathrm{ng} / \mathrm{ml}$; specific gravity-corrected) and microcarcinomas and larger tumor papillary thyroid cancer in Connecticut women

\begin{tabular}{|c|c|c|c|c|c|c|c|c|c|c|}
\hline \multirow[b]{2}{*}{ Organophosphate Flame Retardant (ng/ml) } & \multicolumn{5}{|c|}{ Microcarcinomas (Tumor Diameter $\leq 1 \mathrm{~cm}$ ) } & \multicolumn{5}{|c|}{ Larger Tumor Size (Tumor Diameter > 1 cm) } \\
\hline & Cases & Controls & $\mathrm{OR}^{a}$ & $95 \% \mathrm{Cl}$ & $\overline{p-t r e n d}$ & Cases & Controls & $\mathrm{OR}^{\mathrm{a}}$ & $95 \% \mathrm{Cl}$ & $p$ - trend \\
\hline \multicolumn{11}{|l|}{ BCIPP } \\
\hline$<M D L$ & 32 & 50 & 1 & & & 28 & 50 & 1 & & \\
\hline$\geq M D L-0.45$ & 9 & 25 & 0.52 & $(0.18,1.38)$ & 0.06 & 16 & 25 & 0.99 & $(0.38,2.56)$ & 0.31 \\
\hline$>0.45$ & 6 & 25 & 0.38 & $(0.12,1.09)$ & & 7 & 25 & 0.51 & $(0.15,1.56)$ & \\
\hline Continuous $^{\mathrm{b}}$ & 47 & 100 & 0.84 & $(0.69,1.03)$ & & 51 & 100 & 0.94 & $(0.77,1.14)$ & \\
\hline \multicolumn{11}{|l|}{ DPHP } \\
\hline$<0.59$ & 17 & 33 & 1 & & & 16 & 33 & 1 & & \\
\hline $0.59-1.28$ & 15 & 33 & 0.87 & $(0.33,2.29)$ & 0.61 & 18 & 33 & 0.94 & $(0.33,2.67)$ & 0.57 \\
\hline$>1.28$ & 15 & 34 & 0.78 & $(0.29,2.05)$ & & 17 & 34 & 1.32 & $(0.49,3.64)$ & \\
\hline Continuous $^{\mathrm{b}}$ & 47 & 100 & 0.86 & $(0.56,1.26)$ & & 51 & 100 & 1.08 & $(0.76,1.55)$ & \\
\hline \multicolumn{11}{|l|}{ BDCIPP } \\
\hline$<0.37$ & 15 & 33 & 1 & & & 14 & 33 & 1 & & \\
\hline $0.37-0.96$ & 15 & 33 & 0.76 & $(0.28,2.03)$ & 0.90 & 18 & 33 & 1.02 & $(0.36,2.86)$ & 0.49 \\
\hline$>0.85$ & 17 & 34 & 1.03 & $(0.41,2.65)$ & & 19 & 34 & 1.43 & $(0.51,4.08)$ & \\
\hline Continuous $^{\mathrm{b}}$ & 47 & 100 & 0.98 & $(0.74,1.31)$ & & 51 & 100 & 1.12 & $(0.84,1.51)$ & \\
\hline \multicolumn{11}{|l|}{ IPDPP } \\
\hline$<1.60$ & 17 & 33 & 1 & & & 13 & 33 & 1 & & \\
\hline $1.60-3.56$ & 12 & 33 & 0.79 & $(0.30,2.08)$ & 0.99 & 16 & 33 & 1.00 & $(0.35,2.84)$ & 0.52 \\
\hline$>3.56$ & 18 & 34 & 1.01 & $(0.39,2.55)$ & & 22 & 34 & 1.37 & $(0.50,3.83)$ & \\
\hline Continuous $^{\mathrm{b}}$ & 47 & 100 & 1.06 & $(0.70,1.60)$ & & 51 & 100 & 0.98 & $(0.62,1.54)$ & \\
\hline \multicolumn{11}{|l|}{ BCIPHIPP } \\
\hline$<0.12$ & 18 & 33 & 1 & & & 20 & 33 & 1 & & \\
\hline $0.12-0.32$ & 18 & 33 & 1.06 & $(0.44,2.57)$ & 0.25 & 15 & 33 & 0.81 & $(031,2.10)$ & 0.27 \\
\hline$>0.32$ & 11 & 34 & 0.54 & $(0.19,1.45)$ & & 16 & 34 & 0.57 & $(0.21,1.52)$ & \\
\hline Continuous $^{\mathrm{b}}$ & 47 & 100 & 0.79 & $(0.57,1.06)$ & & 51 & 100 & 0.77 & $(0.59,1.00)$ & \\
\hline \multicolumn{11}{|l|}{ Summed PFR } \\
\hline$<4.10$ & 20 & 34 & 1 & & & 14 & 34 & 1 & & \\
\hline $4.10-7.95$ & 12 & 33 & 0.65 & $(0.25,1.66)$ & & 17 & 33 & 1.37 & $(0.50,3.83)$ & 0.55 \\
\hline$>7.95$ & 15 & 33 & 0.75 & $(0.29,1.93)$ & 0.53 & 20 & 33 & 1.37 & $(0.50,3.79)$ & \\
\hline Continuous $^{\mathrm{b}}$ & 47 & 100 & 0.77 & $(0.47,1.22)$ & & 51 & 100 & 1.02 & $(0.66,1.57)$ & \\
\hline
\end{tabular}

bis(1-chloro-2-propyl) 1-hydroxy-2-propyl phosphate (BCIPHIPP), bis(1-chloro-2-propyl) phosphate (BCPP), diphenyl phosphate (DPP), bis(1,3-dichloro-2-propyl) phosphate (BDCPP), isopropyl-phenyl phenyl phosphate (IP-DPP), and tert-butyl phenyl phenyl phosphate (tb-PPP), odds ratio (OR), $95 \%$ confidence interval (95\% Cl), PFR (organophosphate flame retardant)

${ }^{a}$ Adjusted for age, BMl, education level, family history of thyroid cancer, previous benign thyroid disease, and alcohol consumption

${ }^{\mathrm{b}}$ Based on log-transformed PFR concentrations; odds ratio calculated for each $1 \mathrm{og}$ of $1 \mathrm{ng} / \mathrm{ml}$

dust samples could also be used to as a proxy for past exposures, as they may be representative of longer time periods. However, these measures only capture the home environment and do not capture exposures occurring in vehicles, the workplace, or via dietary intake.

Limitations related to our population were our moderate number of cases $(n=100)$. Also, though our study was population-based, the generalizability is limited to those populations with similar exposures and to Caucasian women. Future studies could explore whether there are associations between PFR exposure and risk of thyroid cancer in men, women of other races and ethnicities, and populations in other geographic regions.

\section{Conclusions}

The widespread PFR exposures within our population were linked to BMI and season. Despite the evidence of disruption of thyroid homeostasis by PFRs, this study does not provide support for an increased risk 
Table 5 Multiplicative change in organophosphate concentration $\left(e^{\beta}\right)$ (specific-gravity corrected) with respect to potential exposure predictors

\begin{tabular}{|c|c|c|c|c|c|c|}
\hline Potential Predictors $^{a}$ & BCIPP & DPHP & BDCIPP & IPIPP & BCIPHIPPP & Sum \\
\hline \multicolumn{7}{|l|}{ BMI (ref: Normal) } \\
\hline Overweight & - & - & $0.98(0.62,1.5)$ & $1.4(1.0,1.9)$ & - & $1.2(0.87,1.6)$ \\
\hline Obese & - & - & $1.6(1.0,2.6)$ & $1.7(1.3,2.4)$ & - & $1.7(1.2,2.3)$ \\
\hline \multicolumn{7}{|l|}{ Year (Ref: 2010) } \\
\hline 2011 & $0.32(0.16,0.64)$ & - & - & - & - & $0.68(0.49,0.93)$ \\
\hline 2012 & $0.27(0.12,0.61)$ & - & - & - & - & $0.64(0.43,0.94)$ \\
\hline 2013 & $0.57(0.23,1.5)$ & - & - & - & - & $0.64(0.42,0.98)$ \\
\hline \multicolumn{7}{|l|}{ Season (Ref: Winter) } \\
\hline Spring & - & - & $1.4(0.80,2.5)$ & $1.5(1.0,1.9)$ & - & $1.4(0.99,2.1)$ \\
\hline Summer & - & - & $2.4(1.3,4.3)$ & $1.7(1.1,2.5)$ & - & $1.7(1.1,2.4)$ \\
\hline Fall & - & - & $1.2(0.69,2.2)$ & $1.6(1.0,2.3)$ & - & $1.2(0.83,1.8)$ \\
\hline Ever Alcohol (Ref: Never) & - & $1.4(1.0,1.9)$ & - & - & - & - \\
\hline Ever Smoker (Ref: never) & - & - & $0.59(0.40,0.89)$ & - & - & - \\
\hline
\end{tabular}

${ }^{a}$ The following variables were not associated with any metabolite concentrations: education, below vs. above poverty level, or age at the level of $p<0.1$

of thyroid cancer associated with exposure to PFRs, measured at the time of diagnosis. Given the biologic plausibility, the relationships between PFR exposure and thyroid cancer risk warrant further investigation in a larger study population with additional biomarker measurements.

\section{Additional file}

Additional file 1: Table S1a. Spearman correlations among organophosphate flame retardants (specific gravity-corrected) $(n=200)$ Table S1b. Spearman correlations among organophosphate flame retardants (not specific gravity-corrected) $(n=200)$. (DOCX $17 \mathrm{~kb})$

\section{Abbreviations}

95\% Cl: 95\% confidence intervals; BCIPHIPP: Bis(1-chloro-2-propyl) 1-hydroxy2-propyl phosphate; BCIPP: Bis(1-chloro-2-propyl) phosphate; BDCIPP: Bis(1,3dichloro-2-propyl) phosphate; BMI: Body mass index; DPHP: Diphenyl phosphate; ip-PPP: Isopropyl-phenyl phenyl phosphate; OR: Odds ratio; PBDE: Polybrominated diphenyl ether; PFRs: Organophosphate flame retardants; SPE: Solid phase extraction; T3: Triiodothyronine; T4: Thyroxine; tbPPP: Tert-butyl phenyl phenyl phosphate; TDCPP: Tris (1,3-dichloro-isopropyl) phosphate; TPHP: Triphenyl phosphate; U.S.: United States

\section{Acknowledgments}

We would like to thank the participants of the Connecticut Thyroid CaseControl study. We also thank Amelia Lorenzo at Duke University for assistance in the analysis of the urine samples.

\section{Funding}

This research was supported by the American Cancer Society grants 127509MRSG-15-147-01-CNE (PI: Deziel), RSGM-10-038-01-CCE (PI: Zhang), the Yale Cancer Center \& American Cancer Society Institutional Research Grant IRG58-012-57 (PI: Deziel). This work was also supported by the National Institutes of Health (NIH) grant R01ES020361 (PI: Zhang). The funding bodies had no involvement in the design of the study, sample collection, analysis, data interpretation, or writing of the manuscript.

\section{Availability of data and materials}

Requests for data and statistical code should be sent to corresponding author for review.

\section{Authors' contributions}

$\mathrm{ND}$ and $\mathrm{YZ}$ designed the study; $\mathrm{NZ}, \mathrm{HH}, \mathrm{YZ}$ collected and assembled and interpreted interview data; $\mathrm{NZ}$ and $\mathrm{HH}$ collected and processed biospecimens; HS conducted laboratory analysis and interpretation; ND and $\mathrm{HY}$ conducted the statistical analyses and wrote the first draft of manuscript; $Y Z, H M, N Z, H S$ provided critical revisions of the manuscript. All authors read and approved the final manuscript.

\section{Ethics approval and consent to participate}

All study procedures were approved by the Human Investigations Committee at Yale (HIC \# 0911005954) and the Connecticut Department of Public Health. All participants provided written informed consent to participate in the study.

\section{Competing interests}

The authors declare that they have no competing interests.

\section{Publisher's Note}

Springer Nature remains neutral with regard to jurisdictional claims in published maps and institutional affiliations.

\section{Author details}

${ }^{1}$ Department of Environmental Health Sciences, Yale School of Public Health, 60 College St, New Haven, CT 06520, USA. Nicholas School of the Environment, Duke University, 9 Circuit Dr, Durham, NC 27710, USA. ${ }^{3}$ Department of Surgery, Yale School of Medicine, 333 Cedar St, New Haven, CT 06510, USA. ${ }^{4}$ Department of Biostatistics, Yale School of Public Health, 60 College St, New Haven, CT 06520, USA.

Received: 15 September 2017 Accepted: 25 May 2018 Published online: 05 June 2018

\section{References}

1. Howlader N, Noone AM, Krapcho M, Miller D, Bishop K, Kosary CL, Yu M, Ruhl J, Tatalovich Z, Mariotto A, Lewis DR, Chen HS, Feuer EJ, Cronin KA (eds). SEER Cancer Statistics Review, 1975-2014; National Cancer Institute. Bethesda, MD, https://seer.cancer.gov/csr/1975_2014/, based on November 2016 SEER data submission, posted to the SEER web site, April 2017.

2. Cancer Facts \& Figures 2017. https://www.cancer.org/research/cancer-factsstatistics.html. Accessed 7 May 2018.

3. Lubitz CC, Kong CY, McMahon PM, Daniels GH, Chen Y, Economopoulos KP, Gazelle GS, Weinstein MC. Annual financial impact of well-differentiated thyroid cancer care in the United States. Cancer. 2014;120(9):1345-52. 
4. Brown AP, Chen J, Hitchcock YJ, Szabo A, Shrieve DC, Tward JD. The risk of second primary malignancies up to three decades after the treatment of differentiated thyroid cancer. J Clin Endocrinol Metab. 2008:93(2):504-15.

5. Kim C, Bi X, Pan D, Chen Y, Carling T, Ma S, Udelsman R, Zhang Y. The risk of second cancers after diagnosis of primary thyroid cancer is elevated in thyroid microcarcinomas. Thyroid. 2013;23(5):575-82.

6. Husson O, Haak HR, Buffart LM, Nieuwlaat WA, Oranje WA, Mols F, Kuijpens $J$, Coebergh JW. Van de poll-Franse LV. Health-related quality of life and disease specific symptoms in long-term thyroid cancer survivors: a study from the population-based PROFILES registry. Acta Oncol. 2013;52(2):249-58

7. Imaizumi M, Ohishi W, Nakashima E, Nobuko S, Neriishi K, Yamada M, et al. Association of radiation dose with prevalence of thyroid nodules among atomic bomb survivors exposed in childhood (2007-2011). JAMA Intern Med. 2015;175(2):228-36

8. Ron E, Lubin JH, Shore RE, Mabuchi K, Modan B, Pottern LM, Schneider AB, Tucker MA, Boice JD Jr. Thyroid cancer after exposure to external radiation: a pooled analysis of seven studies. Radiat Res. 1995;141(3):259-77.

9. Detailed Guide for Thyroid Cancer http://www.cancer.org/cancer/ thyroidcancer/detailedguide/index. Accessed 7 May 2018.

10. Kitahara CM, McCullough ML, Franceschi S, Rinaldi S, Wolk A, Neta G, et al. Anthropometric factors and thyroid Cancer risk by histological subtype: pooled analysis of 22 prospective studies. Thyroid. 2016;26(2):306-18.

11. Rinaldi S, Lise M, Clavel-Chapelon F, Boutron-Ruault MC, Guillas G, Overvad $K$, et al. Body size and risk of differentiated thyroid carcinomas: findings from the EPIC study. Int J Cancer. 2012;131(6):E1004-14.

12. Davies $L$, Welch HG. Current thyroid Cancer trends in the United States. JAMA Otolaryngol Head Neck Surg. 2014;140(4):317-22.

13. Davies $L$, Welch HG. Increasing incidence of thyroid cancer in the United States, 1973-2002. JAMA. 2006;295(18):2164-7.

14. Ward EM, Jemal A, Chen A. Increasing incidence of thyroid cancer: is diagnostic scrutiny the sole explanation? Future Oncol. 2010;6(2):185-8.

15. Chen AY, Jemal A, Ward EM. Increasing incidence of differentiated thyroid cancer in the United States, 1988-2005. Cancer. 2009;115(16): 3801-7

16. Zhu C, Zheng T, Kilfoy BA, Han X, Ma S, Ba Y, Bai Y, Wang R, Zhu Y, Zhang $Y$. A birth cohort analysis of the incidence of papillary thyroid cancer in the United States, 1973-2004. Thyroid. 2009;19(10):1061-6.

17. Cho YY, Jang HW, Joung JY, Park SM, Jeong DJ, Kim SW, et al. Trends in thyroid Cancer incidence in Korean children (1999-2012) based on palpation and nonpalpation detection methods. Eur Thyroid J. 2015;4(4): 252-9.

18. Vergamini LB, Frazier AL, Abrantes FL, Ribeiro KB, Rodriguez-Galindo C. Increase in the incidence of differentiated thyroid carcinoma in children, adolescents, and young adults: a population-based study. J Pediatr. 2014; 164(6):1481-5

19. Aschebrook-Kilfoy B, Grogan RH, Ward MH, Kaplan E, Devesa SS. Follicular thyroid cancer incidence patterns in the United States, 1980-2009. Thyroid 2013;23(8):1015-21.

20. Udelsman R, Zhang $Y$. The epidemic of thyroid cancer in the United States: the role of endocrinologists and ultrasounds. Thyroid. 2014;24(3): 472-9.

21. Aschebrook-Kilfoy B, Ward MH, Sabra MM, Devesa SS. Thyroid cancer incidence patterns in the United States by histologic type, 1992-2006. Thyroid. 2011;21(2):125-34.

22. Enewold L, Zhu K, Ron E, Marrogi AJ, Stojadinovic A, Peoples GE, Devesa SS Rising thyroid cancer incidence in the United States by demographic and tumor characteristics, 1980-2005. Cancer Epidemiol Biomark Prev. 2009;18(3): 784-91.

23. Ba Y, Huang H, Lerro CC, Li S, Zhao N, Li A, Ma S, Udelsman R, Zhang Y. Occupation and thyroid Cancer: a population-based, case-control study in Connecticut. J Occup Environ Med. 2016;58(3):299-305.

24. Hoffman K, Sosa JA, Stapleton HM. Do flame retardant chemicals increase the risk for thyroid dysregulation and cancer? Curr Opin Oncol. 2017;29(1):7-13.

25. Dishaw LV, L JM, Roberts SC, Stapleton HM. Exposures, mechanisms, and impacts of endocrine-active flame retardants. Curr Opin Pharmacol. 2014; 19c:125-33

26. Stapleton HM, Sharma S, Getzinger G, Ferguson PL, Gabriel M, Webster TF, Blum A. Novel and high volume use flame retardants in US couches reflective of the 2005 PentaBDE phase out. Environ Sci Technol. 2012;46(24): 13432-9.
27. Greaves AK, Letcher RJ. A review of organophosphate esters in the environment from biological effects to distribution and fate. Bull Environ Contam Toxicol. 2017;98(1):2-7.

28. Stapleton HM, Allen JG, Kelly SM, Konstantinov A, Klosterhaus S, Watkins $D$, et al. Alternate and new brominated flame retardants detected in $U$. S. house dust. Environ Sci Technol. 2008:42(18):6910-6.

29. Stapleton HM, Klosterhaus S, Eagle S, Fuh J, Meeker JD, Blum A, Webster TF. Detection of organophosphate flame retardants in furniture foam and U.S. house dust. Environ Sci Technol. 2009;43(19):7490-5.

30. California Environmental Protection Agency Department of Toxic Substances Control. Priority Product Profile: Children's Foam-Padded Sleeping Products Containing TDCPP. 2014.

31. Mendelsohn E, Hagopian A, Hoffman K, Butt CM, Lorenzo A, Congleton J, Webster TF, Stapleton HM. Nail polish as a source of exposure to triphenyl phosphate. Environ Int. 2016:86:45-51.

32. Ballesteros-Gomez A, Brandsma SH, de Boer J, Leonards PE. Analysis of two alternative organophosphorus flame retardants in electronic and plastic consumer products: resorcinol bis-(diphenylphosphate) (PBDPP) and bisphenol a bis (diphenylphosphate) (BPA-BDPP). Chemosphere 2014;116:10-4.

33. van der Veen I, de Boer J. Phosphorus flame retardants: properties, production, environmental occurrence, toxicity and analysis. Chemosphere. 2012;88(10):1119-53.

34. Butt CM, Congleton J, Hoffman K, Fang M, Stapleton HM. Metabolites of organophosphate flame retardants and 2-ethylhexyl tetrabromobenzoate in urine from paired mothers and toddlers. Environ Sci Technol. 2014;48(17): 10432-8.

35. Hoffman K, Lorenzo A, Butt CM, Adair L, Herring AH, Stapleton HM, Daniels $J$. Predictors of urinary flame retardant concentration among pregnant women. Environ Int. 2017:98:96-101.

36. Meeker JD, Cooper EM, Stapleton HM, Hauser R. Urinary metabolites of organophosphate flame retardants: temporal variability and correlations with house dust concentrations. Environ Health Perspect. 2013;121(5):580-5.

37. Butt CM, Hoffman $\mathrm{K}$, Chen A, Lorenzo A, Congleton J, Stapleton HM. Regional comparison of organophosphate flame retardant (PFR) urinary metabolites and tetrabromobenzoic acid (TBBA) in mother-toddler pairs from California and New Jersey. Environ Int. 2016;94:627-34.

38. Castorina R, Butt C, Stapleton HM, Avery D, Harley KG, Holland N, Eskenazi B, Bradman A. Flame retardants and their metabolites in the homes and urine of pregnant women residing in California (the CHAMACOS cohort). Chemosphere. 2017;179:159-66.

39. Kosarac I, Kubwabo C, Foster WG. Quantitative determination of nine urinary metabolites of organophosphate flame retardants using solid phase extraction and ultra performance liquid chromatography coupled to tandem mass spectrometry (UPLC-MS/MS). J Chromatogr B. 2016;1014:24-30.

40. Feng L, Ouyang F, Liu L, Wang X, Wang X, Li YJ, et al. Levels of urinary metabolites of organophosphate flame retardants, TDCIPP, and TPHP, in pregnant women in shanghai. J Environ Public Health. 2016;2016:9416054.

41. Farhat A, Crump D, Chiu S, Williams KL, Letcher RJ, Gauthier LT, Kennedy SW. In Ovo effects of two organophosphate flame retardants-TCPP and TDCPP-on pipping success, development, mRNA expression, and thyroid hormone levels in chicken embryos. Toxicol Sci. 2013;134(1):92-102.

42. Liu X, Ji K, Choi K. Endocrine disruption potentials of organophosphate flame retardants and related mechanisms in H295R and MVLN cell lines and in zebrafish. Aquat Toxicol. 2012;114-115:173-81.

43. Liu X, Ji K, Jo A, Moon HB, Choi K. Effects of TDCPP or TPP on gene transcriptions and hormones of HPG axis, and their consequences on reproduction in adult zebrafish (Danio rerio). Aquat Toxicol. 2013;134-135: 104-11.

44. Wang Q, Lai NL, Wang X, Guo Y, Lam PK, Lam JC, Zhou B. Bioconcentration and transfer of the organophorous flame retardant 1,3-dichloro-2-propyl phosphate causes thyroid endocrine disruption and developmental neurotoxicity in zebrafish larvae. Environ Sci Technol. 2015:49(8):5123-32.

45. Xu T, Wang Q, Shi Q, Fang Q, Guo Y, Zhou B. Bioconcentration, metabolism and alterations of thyroid hormones of Tris(1,3-dichloro-2-propyl) phosphate (TDCPP) in zebrafish. Environ Toxicol Pharmacol. 2015;40(2):581-6.

46. Kim S, Jung J, Lee I, Jung D, Youn H, Choi K. Thyroid disruption by triphenyl phosphate, an organophosphate flame retardant, in zebrafish (Danio rerio) embryos/larvae, and in GH3 and FRTL-5 cell lines. Aquat Toxicol. 2015;160c:188-96. 
47. Liu X, Jung D, Jo A, Ji K, Moon HB, Choi K. Long-term exposure to triphenylphosphate alters hormone balance and HPG, HPI, and HPT gene expression in zebrafish (Danio rerio). Environ Toxicol Chem. 2016;35(9):2288-96.

48. Hill KL, Hamers T, Kamstra JH, Willmore WG, Letcher RJ. Organophosphate triesters and selected metabolites enhance binding of thyroxine to human transthyretin in vitro. Toxicol Lett. 2018;285:87-93.

49. Meeker JD. Exposure to environmental endocrine disrupting compounds and men's health. Maturitas. 2010;66(3):236-41.

50. Meeker JD, Cooper EM, Stapleton HM, Hauser R. Exploratory analysis of urinary metabolites of phosphorus-containing flame retardants in relation to markers of male reproductive health. Endocrine Disruptors. 2013;1(1):e26306.

51. Preston EV, McClean MD, Claus Henn B, Stapleton HM, Braverman LE, Pearce EN, Makey CM, Webster TF. Associations between urinary diphenyl phosphate and thyroid function. Environ Int. 2017;101:158-64.

52. Moeller LC, Fuhrer D. Thyroid hormone, thyroid hormone receptors, and cancer: a clinical perspective. Endocr Relat Cancer. 2013;20(2):R19-29.

53. Huang H, Rusiecki J, Udelsman R, Zhang Y. TSH, thyroid hormone, and PTCresponse. Cancer Epidemiol Biomark Prev. 2018;27(2):228-9.

54. Huang H, Rusiecki J, Zhao N, Chen Y, Ma S, Yu H, Ward MH, Udelsman R, Zhang $Y$. Thyroid-stimulating hormone, thyroid hormones, and risk of papillary thyroid Cancer: a nested case-control study. Cancer Epidemiol Biomark Prev. 2017:26(8):1209-18.

55. Franco AT, Malaguarnera R, Refetoff S, Liao XH, Lundsmith E, Kimura S, et al. Thyrotrophin receptor signaling dependence of Braf-induced thyroid tumor initiation in mice. Proc Natl Acad Sci U S A. 2011;108(4):1615-20.

56. Zhang $Y$, Chen $Y$, Huang H, Sandler J, Dai M, Ma S, Udelsman R. Diagnostic radiography exposure increases the risk for thyroid microcarcinoma: a population-based case-control study. Eur J Cancer Prev. 2015;24(5):439-46.

57. Deziel N, Yi H, Stapleton HM, Huang H, Zhao N, Zhang Y. Exposure to Organophosphate Flame Retardants and Thyroid Cancer Risk in Women Abstract Number WE-PO-565. Poster presented at the International Society for Exposure Science Annual Meeting. 2017. Research Triangle Park, North Carolina, United States. https://www.intlexposurescience.org/ISES2017/ ISES2017/Schedule/Online_Program.aspx Accessed 23 May 2018.

58. Hoffman K, Butt CM, Webster TF, Preston EV, Hammel SC, Makey C, et al. Temporal trends in exposure to organophosphate flame retardants in the United States. Environ Sci Technol Lett. 2017:4(3):112-8.

59. Tung EWY, Peshdary V, Gagne R, Rowan-Carroll A, Yauk CL, Boudreau A, et al. Adipogenic effects and gene expression profiling of Firemaster(R) 550 components in human primary Preadipocytes. Environ Health Perspect. 2017;125(9):097013.

60. Xu F, Giovanoulis G, van Waes S, Padilla-Sanchez JA, Papadopoulou E, Magner J, et al. Comprehensive study of human external exposure to organophosphate flame retardants via air, dust, and hand wipes: the importance of sampling and assessment strategy. Environ Sci Technol. 2016;50(14):7752-60.

61. Hoffman K, Daniels JL, Stapleton HM. Urinary metabolites of organophosphate flame retardants and their variability in pregnant women. Environ Int. 2014;63: 169-72.

\section{Ready to submit your research? Choose BMC and benefit from:}

- fast, convenient online submission

- thorough peer review by experienced researchers in your field

- rapid publication on acceptance

- support for research data, including large and complex data types

- gold Open Access which fosters wider collaboration and increased citations

- maximum visibility for your research: over $100 \mathrm{M}$ website views per year

At BMC, research is always in progress.

Learn more biomedcentral.com/submissions 